\title{
Depositional age and geochemistry of the 2.44-2.32 Ga Granular Iron Formation, Songshan Group, North China Craton: Tracing the effects of atmospheric oxygenation on continental weathering and seawater environment

\author{
CAIYUN LAN ${ }^{1}$, XIAOPING LONG ${ }^{2}$
} \\ ${ }^{1}$ State Key Laboratory of Continental Dynamics, Department of Geology, Northwest University, Xi'an 710069, China.E-mail address: lancaiyun@nwu.edu.cn ${ }^{2}$ State Key Laboratory of Continental Dynamics, \\ Department of Geology, Northwest University, Xi'an \\ 710069, China. E-mail address: longxp@nwu.edu.cn
}

We firstly found that Granular Iron Formation (GIF) occurring in the Songshan Group of the North China Craton was deposited at the period of 2.44-2.32 Ga via detrital and magmatic zircon $\mathrm{U}-\mathrm{Pb}$ dating. Positive $\delta^{13} \mathrm{C}$ excursion in carbonates located in the upper and lower levels of the GIF in the Songshan Group further indicates elevation of atmospheric oxygen at 2.44-2.32 Ga. No significant correlations between redox-sensitive trace elements $(\mathrm{Cr}, \mathrm{V}$, $\mathrm{Mo}$ and $\mathrm{U}$ ) and $\mathrm{Al}_{2} \mathrm{O}_{3}$ suggest that they are authigenic enrichments in the Songshan GIF. The enrichment of $\mathrm{Cr}$ contents and $\mathrm{Cr} / \mathrm{Ti}$ ratios of the Songshan GIF and its authigenic hematite indicate that $\mathrm{Cr}$ was solubilized via strong continental oxidized weathering and subsequently $\mathrm{Cr}$ rich drainage contributes to seawater. In addition, very high $\mathrm{V}, \mathrm{B}$ and $\mathrm{P}$ contents in the Songshan GIF and its hematite also suggest continental oxidative weathering input. The Songshan GIF and its hematite exhibit significantly positive Ce anomalies and negative $\mathrm{Y}$ anomalies, which is different from most early Paleoproterozoic to Archean and after GOE IFs. These features probably resulted from Fe(II) slowly oxidation and deposition and further indicated shallow waters at 2.44-2.32 Ga were oxygenated but not enough for $\mathrm{Fe}$ (II) rapidly oxidation. Given that soluble $\mathrm{Cr}$ (VI) and V (V) transform into $\mathrm{Cr}$ (III) and V (III) in suboxic-anoxic bottom waters and then are removed via authigenic burial, high $\mathrm{Cr}$ and $\mathrm{V}$ contents of the Songshan GIF and its authigenic hematite favor a scenario for deposition of the GIF in which precipitation occurred due to upwelling of deep, anoxic, reduced $\mathrm{Cr}-\mathrm{V}$-rich ferruginous waters into an oxygenated, high productivity shallow-water setting. Oxidation of shallow water at ca. $2.45-2.10 \mathrm{Ga}$ is a gradual process. 